\title{
Long non-coding RNA $M Y U$ promotes prostate cancer proliferation by mediating the miR-184/c-Myc axis
}

\author{
JINHUA WANG ${ }^{1,2}$, XIAOHUI YANG ${ }^{2}$, RONG $^{2}{ }^{2}$, LIANG WANG $^{3}$, YINMIN GU $^{2}$, \\ YUHUI ZHAO ${ }^{3}$, KUO HSIANG HUANG ${ }^{2}$, TIANYOU CHENG $^{4}$, YI YUAN ${ }^{5}$ and SHAN GAO $^{2,4,5}$
}

\begin{abstract}
${ }^{1}$ School of Life Sciences, University of Science and Technology of China, Hefei, Anhui 230026; ${ }^{2}$ CAS Key Laboratory of Bio-medical Diagnostics, Suzhou Institute of Biomedical Engineering and Technology, Chinese Academy of Sciences, Suzhou, Jiangsu 215163; ${ }^{3}$ CAS Key Laboratory of Pathogenic Microbiology and Immunology, Institute of Microbiology, Chinese Academy of Sciences, Beijing 100101; ${ }^{4}$ Shanxi Academy of Advanced Research and Innovation, Taiyuan, Shanxi 030032; ${ }^{5}$ Medical College, Guizhou University, Guiyang, Guizhou 550025, P.R. China
\end{abstract}

Received February 26, 2018; Accepted August 13, 2018

DOI: 10.3892/or.2018.6661

\begin{abstract}
Long non-coding RNAs (IncRNAs) play critical roles in tumorigenesis and cancer progression. The c-Myc upregulated lncRNA MYU (VPS9D1 antisense RNA1, annotated as VPS9D1-AS1) has been reported in several common types of human cancers, which has revealed that IncRNA MYU could function as either an oncogene or a tumor-suppressor gene in different cancer types. However, the function of lncRNA $M Y U$ in prostate cancer remains unknown. In the present study, we demonstrated that $\operatorname{lncRNA} M Y U$ is significantly upregulated in prostate cancer tissues. $M Y U$ knockdown impaired prostate cancer cell growth and migration as shown from cell viability, colony formation, Transwell and wound healing assays. In contrast, $M Y U$ overexpression displayed opposite effects. No correlation was noted between $M Y U$ and its cognate VPS9D1 expression level. Moreover, IncRNA $M Y U$ did not regulate the expression of VPS9D1 either at the mRNA or protein level as detected using qRT-PCR and western blotting assays. Furthermore, $\operatorname{lncRNA} M Y U$ was able to be transported into the extracellular milieu by means of exosomes, and then promoted adjacent cell proliferation and migration. Mechanistically, lncRNA $M Y U$ upregulated c-Myc by competitively binding miR-184 and then induced the proliferation of prostate cancer. Thus, this study demonstrated that lncRNA $M Y U$ functions as an oncogene in prostate cancer at least in part through the miR-184/c-Myc axis, and may serve as a potential diagnostic biomarker and therapeutic target.
\end{abstract}

Correspondence to: Professor Shan Gao, CAS Key Laboratory of Bio-medical Diagnostics, Suzhou Institute of Biomedical Engineering and Technology, Chinese Academy of Sciences, 88 Keling Road, High-tech District, Suzhou, Jiangsu 215163, P.R. China

E-mail: gaos@sibet.ac.cn

Key words: prostate cancer, long non-coding RNA, $M Y U$, miR-184, c-Myc

\section{Introduction}

Prostate cancer $(\mathrm{PCa})$ is the most common non-cutaneous malignancy in men (1). PCa tumorigenesis is involved in multiple genomic alterations (2). For example, the oncogene $c-M y c$ is upregulated in $\mathrm{PCa}$, which is associated with tumor progression $(3,4)$. A previous study revealed that an HP1 $\gamma /$ miR-451a/c-Myc feedback loop exists in PCa cells and this loop is essential for PCa development (5). However, the underlying molecular mechanisms of c-Myc in PCa remain incompletely understood.

Accumulating evidence indicates that non-coding RNAs (ncRNAs), such as microRNAs (miRNAs, $<200 \mathrm{nt}$ ) and long ncRNAs (lncRNAs, $>200 \mathrm{nt}$ ) (6), are involved in numerous processes of tumorigenesis $(7,8)$. Accumulating data suggest that lncRNAs, such as PCA3 (9), PCAT-1 (4), SChLAPI (10), PCGEMI and PRNCRI (11) play important roles in PCa tumorigenesis. lncRNAs can regulate coding gene mRNAs via competitively binding to co-target miRNAs, termed as competing endogenous RNA (ceRNA) network, thus functioning in cancer $(12,13)$. The molecular mechanism of most lncRNAs in PCa remains unknown due to their enormousness.

A c-Myc-upregulated lncRNA MYU (ENSG00000261373) has been reported to exert an oncogenic effect in colorectal cancer (CRC) $(14,15)$, but functions as a tumor-suppressor gene in gastric cancer (GC) (16). A recent study suggests that $M Y U$ as a target for $\mathrm{Wnt} / \mathrm{c}-\mathrm{Myc}$ signaling can promote cell cycle progression by stabilizing CDK6 expression via associating with hnRNP-K (14). However, the functional roles and underlying molecular mechanisms of $M Y U$ in PCa have not been explored. Thus, we were motivated to study the roles of $M Y U$ in PCa.

In the present study, we revealed the clinical significance and function of $M Y U$ in $\mathrm{PCa}$, and demonstrated that $M Y U$ promotes the progression of $\mathrm{PCa}$ as a ceRNA to modulate miR-184 binding, consequently regulating c-Myc expression. Our results shed new light on the prospect for $M Y U$ as a potential novel diagnostic biomarker as well as a therapeutic target. 


\section{Materials and methods}

Cell culture. Human PCa cell lines DU145, PC3, 22Rv1 and LNCaP were obtained from the Shanghai Institute of Biochemistry and Cell Biology (CAS). Lenti-X ${ }^{\text {тм } 293 T ~ c e l l s ~}$ were obtained from Clontech Laboratories, Inc. (Mountainview, CA, USA). Cell lines were cultured routinely in RPMI-1640 medium (Gibco; Thermo Fisher Scientific, Inc., Waltham, MA, USA) or DMEM (Gibco; Thermo Fisher Scientific, Inc.) supplemented with $10 \%$ fetal bovine serum (FBS, Gibco; Thermo Fisher Scientific, Inc.), penicillin and streptomycin (x100). All cells were maintained in $5 \% \mathrm{CO}_{2}$ at $37^{\circ} \mathrm{C}$. PCR detection method was used to check mycoplasma contamination. All cell lines were verified using short tandem repeat assays by Genetic Testing Biotechnology, Suzhou, China.

5'/3' Rapid amplification of cDNA ends (5'/3' RACE). The complementary DNA (cDNA) was synthesized using RNA $(1.0 \mu \mathrm{g})$ extracted from PC3 cells. The 5'/3' RACE was carried out using the SMARTer ${ }^{\mathrm{TM}}$ RACE cDNA Amplification kit (Clontech Laboratories, Inc.) according to the manufacturer's instructions. The gene-specific primers used for the PCR of the RACE analysis are given in Table I.

Plasmid construction. The full-length of $M Y U$ (Fig. 1) and VPS9D1, which is fused with a FLAG epitope tag with the $\mathrm{C}$ terminus, Fig. 2) were subcloned into pLVX-IRES-Neo vector. The short hairpin RNAs (shRNAs) that target different sites of $M Y U, V P S 9 D 1$ and $c-M y c$ CDS region were inserted into the pSIH1-H1 vector. The shRNA primers are listed in Table II. $M Y U$ full-length and 3' untranslated regions (UTR) of c-Myc containing the miR-184 binding sites were synthesized in the dual luciferase reporter vector pmirGLO (Promega Corporation, Madison, WI, USA).

RNA extraction, quantitative real-time PCR ( $q R T-P C R)$ and Western blotting. Total RNA was isolated from PCa cells using RNAiso Plus reagent (Takara, Shiga, Japan) and RNA $(1 \mu \mathrm{g})$ was reverse transcribed using the PrimerScript RT-PCR kit (Takara) according to the manufacturer's instructions. The expression levels of $M Y U$ were determined by qRT-PCR using the $\mathrm{SYBR}^{\circledR}$ Green dye (Takara) detection method. We used the comparative $\mathrm{Ct}$ method to quantify transcripts. The relative gene expression was defined using the equation: $\Delta \mathrm{Ct}=\mathrm{Ct} \mathrm{target}_{\text {- }}-\mathrm{Ct}_{\text {reference }}$, and the fold-change for target genes normalized by GAPDH was determined by the formula $2^{-\Delta \Delta C t}$.

Total cell lysates were prepared using RIPA reagent (Beyotime, Shanghai, China) and sodium dodecyl sulfate (SDS) loading buffer (Beyotime). The concentration of total proteins was examined using BCA protein kit (Beyotime). Equivalent quantities of proteins were loaded to each lane. SDS-polyacrylamide gel electrophoresis (SDS-PAGE) was used to separate proteins and then the proteins were transferred from the gel onto NC or PVDF membranes. Membranes were incubated with primary antibodies against GAPDH (AG019, 1:5,000), H3 (AH433, 1:5,000) and $\beta$-actin (AA128, 1:5,000) all from Beyotime, Flag (F3165, 1:1,000) from Sigma-Aldrich; Merck KGaA (Darmstadt, Germany), ZO-1 (8193S, 1:1,000), caludin-1 (13995S, 1:1,000), E-cadherin (3195S, 1:1,000), and c-Myc (13987S, 1:1,000) from Cell Signaling Technology, Inc.
Table I. Primers for the 5'/3' RACE.

\begin{tabular}{ll}
\hline Primers & \multicolumn{1}{c}{ Sequence } \\
\hline P1 & 5' CTCTGGGAAGTGGCCGTTTT 3' \\
P2 & 5' GCGCTCCAAGATTGAGGAGT 3' \\
P3 & 5' CTGTTCGTACTCCAGGATGGC3' \\
P4 & 5' CATGCCAAGCTACGGGAAGG 3' \\
P5 & 5' TCTGTCTTCTGGGACTTTGCTC 3' \\
P6 & 5' AGGATGGGAGCAGTAAACGG 3' \\
5'-F & 5' AGGCGGCTCTGACCCCG 3' \\
3'-R & 5' ATCTCCCAGGTGTTACTAGAAGAAGTGG 3' \\
GSP1 & 5' GATTACGCCAAGCTTTTTGCTCCTGCCCCATCTGCC 3' \\
GSP2 & 5' GATTACGCCAAGCTTGGCAGATGGGGCAGGAGCAAA 3'
\end{tabular}

(Danvers, MA, USA), N-cadherin (ab76011, 1:1,000), vimentin (ab92547, 1:1,000) from Abcam (Cambridge, MA, USA). After incubation with suitable HRP-conjugated secondary antibodies, immunoreactive proteins were finally visualized using ECL chemiluminescence system (CLiNX, Shanghai, China). All qRT-PCR primers are listed in Table III.

Subcellular fractionation. LNCaP cells were captured with $1 \mathrm{ml} \mathrm{PBS}$ and $200 \mu \mathrm{l}$ were extracted as the positive control, the reminder were snap-frozen with liquid nitrogen and then quickly dissolved in a water bath, repeating this operation twice. Then, $200 \mu \mathrm{l}$ buffer A1 (10 mM HEPES, pH 7.9, $1.5 \mathrm{mM}$ $\mathrm{MgCl}_{2}, 10 \mathrm{mM} \mathrm{KCl}, 0.1 \% \mathrm{NP}-40$ and $1 \%$ protease inhibitor) was added to the cells, and ground 15-20 times with a grinding pestle. After incubation on ice for $5 \mathrm{~min}$, the lysate was centrifuged at 2,000 rpm for $5 \mathrm{~min}$ at $4^{\circ} \mathrm{C}$. The supernatant was used to separate the cytoplasmic fraction. The remaining pellet was resuspended in $200 \mu \mathrm{l}$ of buffer A2 (10 mM HEPES, pH 7.9, $1.5 \mathrm{mM} \mathrm{MgCl}_{2}, 10 \mathrm{mM} \mathrm{KCl}$, and $1 \%$ protease inhibitor) and ground 5-10 times with a grinding pestle. Then, the lysate was resuspended in another $300 \mu \mathrm{l}$ of buffer A2. After incubating on ice for $5 \mathrm{~min}$, the lysate was centrifuged at $2000 \mathrm{rpm}$ for $5 \mathrm{~min}$ at $4^{\circ} \mathrm{C}$. The remaining pellet was resuspended in $500 \mu \mathrm{l}$ of buffer $\mathrm{S} 1\left(0.25 \mathrm{mM}\right.$ sucrose, $10 \mathrm{mM} \mathrm{MgCl}_{2}$, and $1 \%$ protease inhibitor), and then added $500 \mu \mathrm{l}$ of buffer S2 ( $0.35 \mathrm{mM}$ sucrose, $0.5 \mathrm{mM} \mathrm{MgCl}$, and $1 \%$ protease inhibitor) slowly from the top of the liquid. The lysate was centrifuged at 3,500 $\mathrm{rpm}$ for $5 \mathrm{~min}$ at $4^{\circ} \mathrm{C}$. The remaining pellet was resuspended in $200 \mu \mathrm{l}$ RIPA buffer (50 mM Tris, pH 7.5, $150 \mathrm{mM}$ $\mathrm{NaCl}, 1 \% \mathrm{NP}-40$, and $0.5 \%$ deoxycholate) and incubated on ice for $30 \mathrm{~min}$. The supernatant containing the nuclear fraction was collected by centsrifugation at $12,000 \mathrm{rpm}$ for $15 \mathrm{~min}$ at $4^{\circ} \mathrm{C}$. qRT-PCR and western blot analysis were used to assess the total RNA and protein isolated from the subcellular fractions. GAPDH served as the cytoplasmic control, and U1 as nuclear control. GAPDH, U1 and $M Y U$ expression levels were measured by qRT-PCR.

Cell transfection. The packaging plasmids, recombined plasmids and LNAs for overexpression and knockdown were transfected into Lenti-X ${ }^{\mathrm{TM}}$ 293T cells. Two LNAs (LNA-1 and LNA-2) and LNA-Ctrl (300610, Negative control A 


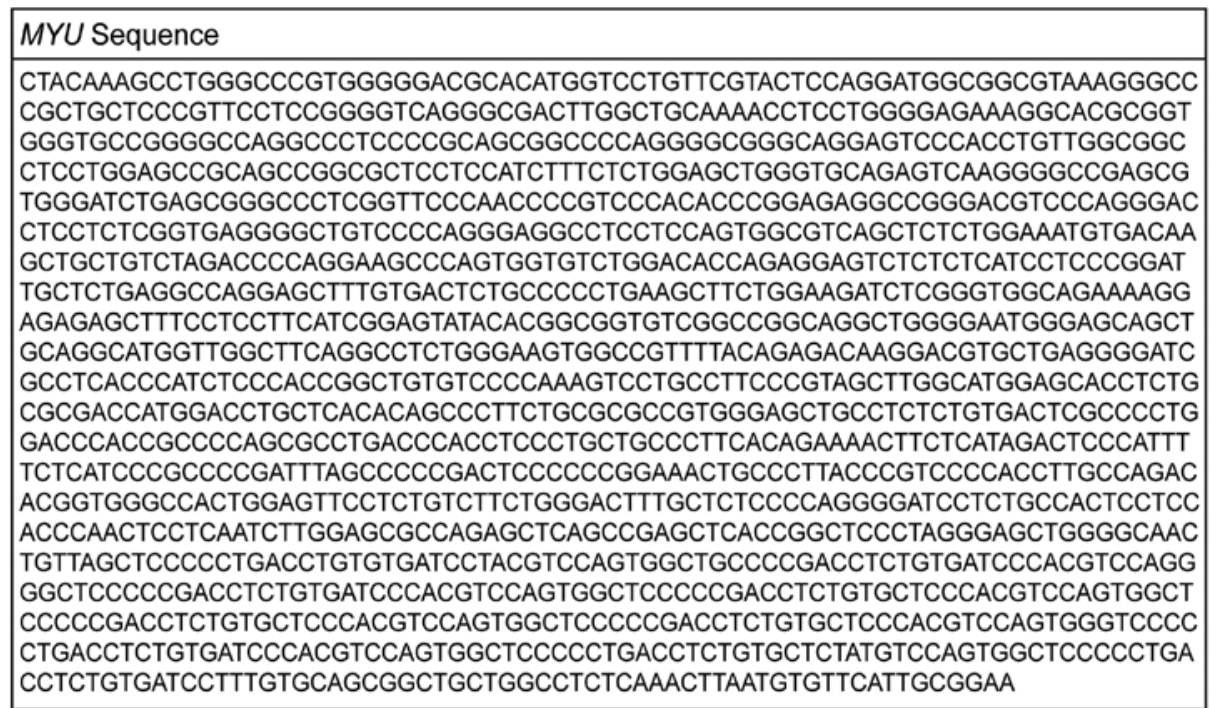

Figure 1. The nucleotide sequence of full-length $M Y U . M Y U$ is a 1,461 bp transcript with four exons.

\begin{tabular}{|l|}
\hline VPS9D1 Sequence \\
\hline ATGGCCGCTGCGGCCGGGGACGGCACGGTGAAGCCGCTGCAGAGCGCCATGAAGCTTGCCAACGGG \\
GCCATCGAGCTGGACACCGGCAACCGGCCCCGGAGGCATACACGGAATACCTGAGGAGCATCCACTA \\
TATCTCCCAGGTGTTACTAGAAGAAGTGGAACCACTAAAGAAGCTGGGGAAACTGTGCCCCCGACAC \\
CTCCAAGATGCTGAAGCTAGCACAGCAGTGTCTGGAGAGGCCCAGTCGACGGCCGCCAAGCTTGGGA \\
AAACACGCCTGAAGCCAACCATGCCTGCAGCTGCTCCCATTCCCCAGCCTGCCGGCCGACACCGCCGT \\
GTATACTCCGATGAAGGAGGAAACTCTCTCCTTTCTGCCACCCGAGATCTTCCAGAAGCTTCAGGG \\
GCAGAGTCACAAAGCTGTAAGAAAGAGCTGACGCCACTGGAGGAGGCCTCCCTGCAGAATCAGAAGCT \\
GAAGGCTGCGTATGAGGCCCGAATGGCGCGCTAGACCCCAGCCAGGCCATGCAGAAGACATCCCTGA \\
CCCTCTCTCTACAGCGGCAGATGATGGAGAACCTAGTGATTGCCAAAGCCCGGGAGGAGACACTCCAGA \\
GAAAGATGGAGGAGCGCCGGCTGCGGCTCCAGGAGGCCGCCAACAGGAGGTTTTGCAGCCAAGTCGC \\
CCTGACCCCGGAGGAACGGAGCAGCGGGCCCTTTACGCGCCATCCTGGAGTACGAACAGGACCAT \\
GACTGGCCGAAGCACTGGAAGGCCAAGCTCAAGAGGAATCCGGGGGACCTGTCACTCGTGACCAGCC \\
TGGTCTCACACCTGCTCAGCCTCCCCGACCACCCGATCGCGCAGCTCCTGAGGCGGCTGCAGTGCTCC \\
GTGTACAGCGCCCTGTATCCCGCCGTGAGCAGAGCAGCCGCGCCAGCCCCAGGCTGCTGCCCCCCGA \\
CCCCCAACCCCGGAAGCCGACGGCTGCGGCCCTCGCAGAGCCTCCATTGCATGCTGTCCCCGCCCGA \\
GCCCAGCGCAGCCCCGCGGCCCCAGGACAGTCCCCCCACGCCCCCACTCCAACCCGGCCCCGTGGG \\
GTCTCCCTCACCCCTGGGGGACACCGCATCTGGATTGCCAGACAAGGACAGCTCGTTCGAGGACCTGG \\
AGCAGTTCCTGGGGACGTCTGAGCGGCAGGGCCGGGGCCGTGGGGTACAGCCGGAGCCCCAGCTGC \\
AGCAGCTGAAGACCGCGGTGGAGGAGATCCACAATGCCGTAGACAGGCTGCTCTCGCTGACCCTTCTG \\
GCCTTCGAAGGCCTAAACACAGCTGCCTCCAAGGACCGCTGCCTGGCCTGCATTGAGGAACCCTTTTTC \\
TCCCCGCTGTGGCCTCTGCTGCTGGCCCTGTACAGGAGCGTGCACCGAGCCCGGGAGGCTGCCCTGA \\
GCAGGAGCATGGAGCTCTACAGGAATGCACCCCCCACCGCCATTGGCATCCCCACCAAGCTCCTCCCC \\
CAGAACCCTGAGGCCAAGGGGGCCACTGGCTACCCCTACTGCGCGGCGGCCCAGGAGCTCGGACTGC \\
TGGTCCTGGAGAGCTGCCCCCAGAAGAAGCTGGAGTGCATAGTGCGGACCCTGCGGATCATCTGTGTC \\
TGTGCGGAAGACTACTGCCCCACCCCAGAGGCCACACCCCAGGCCGGGCCCCCGCCCATCGCTGCAG \\
CTGCCATTGGTGCCGATGACCTGCTGCCCATCCTGTCCTTCGTGGTGCTGAGGAGCGGCCTCCCTCAG \\
CTGGTGTCGGAGTGCGCGGCCCTGGAGGAGTTCATCCACGAGGGGTACCTGATCGGAGAGGAGGGCT \\
ACTGCCTCACATCACTGCAGAGTGCCCTGAGCTACGTGGAGCTGCTGCCCCGGGGAGGCCTGGCCAAG \\
gactacaagatgacgatgacaaagactacaaggatgaggatgacaagactacaaggatgacgatgacaaaTAG \\
\hline
\end{tabular}

Figure 2. The nucleotide sequence of VPS9D1 CDS (NCBI: NM_004913.2). Three repeated Flag tag sequences are added to the 3' end of VPS9D1. The lowercase English letters represent duplicate Flag tags.

Antisense LNA GapmeR) were purchased from Exiqon A/S (Vedbaek, Denmark). The hsa-miR-184 (miR-184) mimics and the negative control miR-NC were purchased from RiboBio (Guangzhou, China). Cells were harvested $48 \mathrm{~h}$ after transfection. These corresponding plasmids or miRNA mimics were transfected with PEI or Lipofectamine 3000 (Invitrogen; Thermo Fisher Scientific, Inc.). The final concentrations of miRNAs/LNAs employed in this study were as follows: miR-184 mimic/negative control mimic $50 \mathrm{nM} / \mathrm{ml}$ and LNA-1/ LNA-2/LNA-Ctrl $50 \mathrm{nM} / \mathrm{ml}$.

Cell viability, colony formation and migration assay. Cells were seeded into 96 -well plates at a density of
$1.0 \times 10^{3}$ cells/well. Cell viability was assessed using CellTiter-Glo (CTG) reagent (Promega Corporation) every $48 \mathrm{~h}$ following the manufacturer's instructions. In addition, $1.0 \times 10^{3}$ cells were seeded per well of 6 -well plates. After 2 weeks, the number of clones was counted with staining using ImageJ (https://imagej.nih.gov/ij/). Wound healing and Transwell chamber assays were performed to determine cell migration ability. For wound healing assay, cells were seeded into two well silicones (ibidi, GmbH, Munich, Germany) in 24-well plates. When the cell density reached 90-100\% confluence, the inserts were removed and washed with PBS, and then cultured with serum-free medium. Images were collected at 0 and $24 \mathrm{~h}$ under an inverted microscope (Ziess, 
Table II. Primer sequences of $M Y U, V P S 9 D 1$ and $c-M y c$ shRNAs.

\begin{tabular}{|c|c|c|}
\hline shRNA & Primers & Primer sequence \\
\hline \multirow[t]{2}{*}{ MYU shRNA-1 } & Forward & $\begin{array}{l}\text { 5' GATCCGACCATGGACCTGCTCACACAGCCCTTCTTTCAAGA } \\
\text { GAAGAAGGGCTGTGTGAGCAGGTCCATGGTCTTTTTTG 3' }\end{array}$ \\
\hline & Reverse & $\begin{array}{l}\text { 5' AATTCAAAAAAGACCATGGACCTGCTCACACAGCCCTTCTTC } \\
\text { TCTTGAAAGAAGGGCTGTGTGAGCAGGTCCATGGTCG 3' }\end{array}$ \\
\hline \multirow[t]{2}{*}{ MYU shRNA-2 } & Forward & $\begin{array}{l}\text { 5' GATCCGCCACTGGAGTTCCTCTGTCTTCTGGGACTTCAAGAG } \\
\text { AGTCCCAGAAGACAGAGGAACTCCAGTGGCTTTTTTG 3' }\end{array}$ \\
\hline & Reverse & $\begin{array}{l}\text { 5' AATTCAAAAAAGCCACTGGAGTTCCTCTGTCTTCTGGGACTC } \\
\text { TCTTGAAGTCCCAGAAGACAGAGGAACTCCAGTGGCG 3' }\end{array}$ \\
\hline \multirow[t]{2}{*}{ VPS9D1 shRNA-1 } & Forward & $\begin{array}{l}\text { 5' GATCCTCCACTATATCTCCCAGGTGTTACTAGAATTCAAGAG } \\
\text { ATTCTAGTAACACCTGGGAGATATAGTGGATTTTTTG 3' }\end{array}$ \\
\hline & Reverse & $\begin{array}{l}\text { 5' AATTCAAAAAATCCACTATATCTCCCAGGTGTTACTAGAATCT } \\
\text { CTTGAATTCTAGTAACACCTGGGAGATATAGTGGAG 3' }\end{array}$ \\
\hline \multirow[t]{2}{*}{ VPS9D1 shRNA-2 } & Forward & $\begin{array}{l}\text { 5' GATCCGCAGATGATGGAGAACCTAGTTTCAAGAG } \\
\text { AACTAGGTTCTCCATCATCTGCTTTTTTG 3' }\end{array}$ \\
\hline & Reverse & $\begin{array}{l}\text { 5' AATTCAAAAAAGCAGATGATGGAGAACCTAGTTCTCT } \\
\text { TGAAACTAGGTTCTCCATCATCTGCG 3' }\end{array}$ \\
\hline \multirow[t]{2}{*}{ c-Myc shRNA } & Forward & $\begin{array}{l}\text { 5' GATCCCAGCGAGGATATCTGGAAGAAATTCGAGCTTCAA } \\
\text { GAGAGCTCGAATTTCTTCCAGATATCCTCGCTGTTTTTTG 3' }\end{array}$ \\
\hline & Reverse & $\begin{array}{l}\text { 5' AATTCAAAAAACAGCGAGGATATCTGGAAGAAATTCGAGC } \\
\text { TCTCTTGAAGCTCGAATTTCTTCCAGATATCCTCGCTGG 3' }\end{array}$ \\
\hline
\end{tabular}

Table III. qPCR sequences of MYU, VPS9D1, c-Myc and U1.

\begin{tabular}{lll}
\hline Gene & Primers & \multicolumn{1}{c}{ Sequence } \\
\hline$M Y U$ & Forward & 5' AGTGGCCGTTTTACAGAGACA 3' \\
& Reverse & 5' CATGCCAAGCTACGGGAAGG 3' \\
GAPDH & Forward & 5' GGAGCGAGATCCCTCCAAAAT 3' \\
& Reverse & 5' GGCTGTTGTCATACTTCTCATGG 3' \\
VPS9D1 & Forward & 5' AGATCCACAATGCCGTAGAC 3' \\
& Reverse & 5' CTTGGAGGCAGCTGTGTTTAG 3' \\
$c-M y c$ & Forward & 5' TAGTGGAAAACCAGCAGCCT 3' \\
& Reverse & 5' AGAAATACGGCTGCACCGAG 3' \\
U1 & Forward & 5' GGGAGATACCATGATCACGAAGGT 3' \\
& Reverse & 5' CCACAAATTATGCAGTCGAGTTTCCC 3' \\
\end{tabular}

Jena, Germany). Wound healing images were analyzed using ImageJ. For the Transwell chamber assay, the cell suspension, $3.5 \times 10^{4}$ cells/well in $200 \mu \mathrm{l}$, was added to a $8.0-\mu \mathrm{m}$ pore-size insert of a 24-well plate (Corning Costar, Corning, NY, USA). The lower well was filled with $500 \mu 1$ medium with $10 \%$ FBS. The Transwell plate was then incubated for $24 \mathrm{~h}$ at $37^{\circ} \mathrm{C}$ with $5 \% \mathrm{CO}_{2}$. Hereafter, the cells on the top surface of the insert were wiped off and the cells on the lower surface of the insert were fixed with $95 \%$ ethanol for 10-15 min, and then dyed with $0.5 \%$ crystal violet. Images were collected under an inverted microscope. Finally, the cells were decolorized with $95 \%$ ethanol and the same amount of eluent was used to measure the absorbance at $580 \mathrm{~nm}$ wavelength. These experiments were conducted in triplicate.

Exosome isolation and treatment. PC3 cells were grown to a 70-80\% confluent monolayer, washed three times with PBS, and grown in serum-free culture medium for 3 days. Exosomes were collected by gradient centrifugation, cleaned by PBS, and stored at $-80^{\circ} \mathrm{C}$.

Exosomes were isolated from the $M Y U$-overexpressing or control PC3 supernatant. An appropriate amount of serumfree 1640 medium was added and filtered with a $0.22-\mu \mathrm{m}$ filter. For cell viability assay, PC 3 cells were plated in a 96-well plate on the first day, and then treated with exosomes from $M Y U$-overexpressing or control PC3 cells, which were assessed by CTG assays after incubation for 5 days. For Transwell assays, the PC 3 cell suspension, $3.5 \times 10^{4}$ cells/well in $200 \mu \mathrm{l}$, was added to an $8.0-\mu \mathrm{m}$ pore-size insert of a $24-w e l l$ plate. The lower well contained $500 \mu \mathrm{l}$ exosomes and $10 \%$ FBS. The Transwell plate was then incubated for $24 \mathrm{~h}$ at $37^{\circ} \mathrm{C}$ with $5 \% \mathrm{CO}_{2}$.

Dual luciferase reporter assay. Lenti-X ${ }^{\mathrm{TM}}$ 293T cells grown in a 24-well plate were co-transfected with $200 \mathrm{ng}$ of dual luciferase reporter vector comprising $M Y U$ and its mutant or 3'UTR of c-Myc, $50 \mathrm{nM}$ miRNA mimics using Lipofectamie 3000. Cells were harvested $48 \mathrm{~h}$ after transfection and analyzed using the dual luciferase reporter assay kit (Promega Corporation) with a microplate reader (BioTek Instruments, Inc., Winooski, VT, USA) according to the manufacturer's protocol. 
A
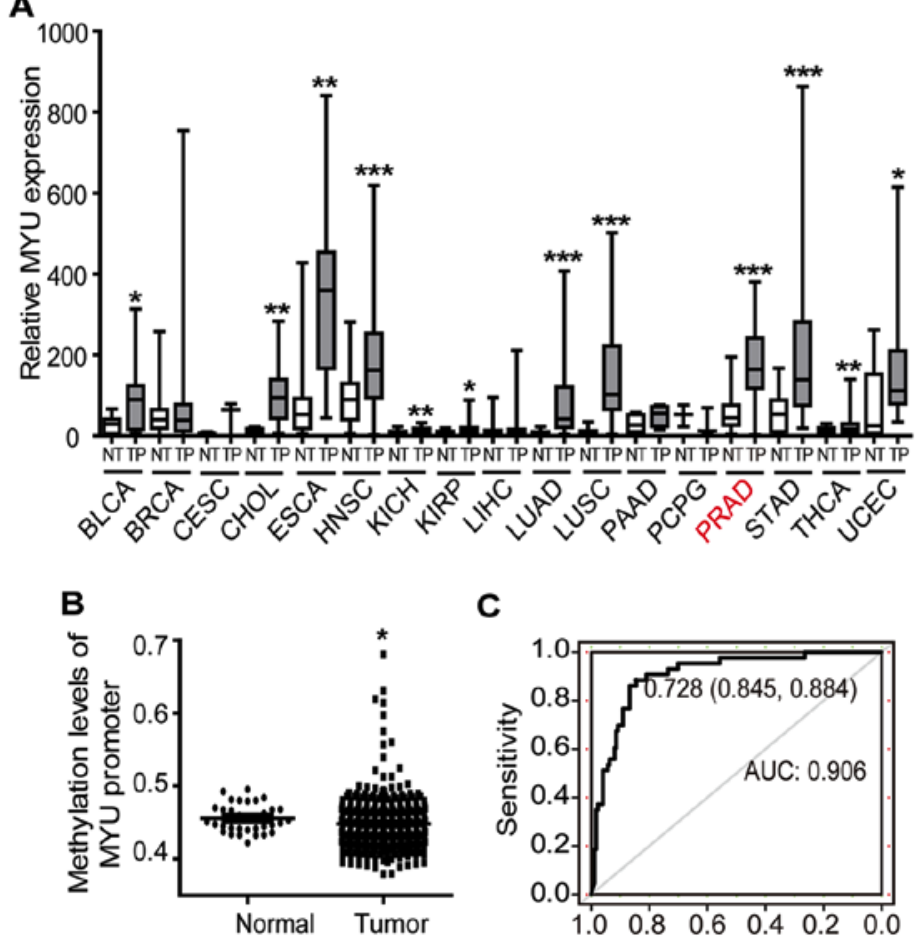

C

D
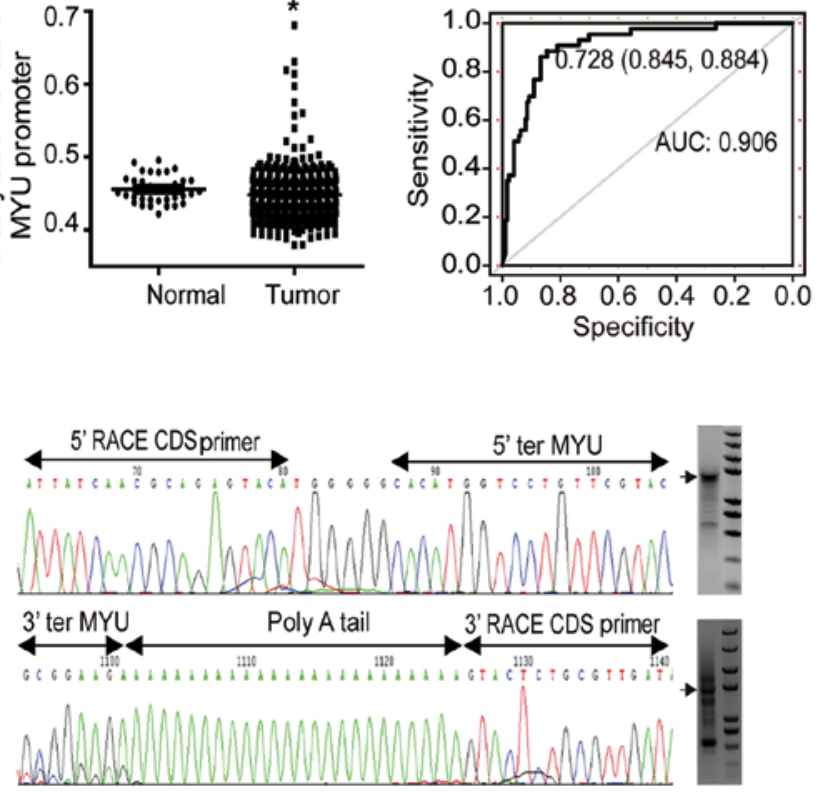

E

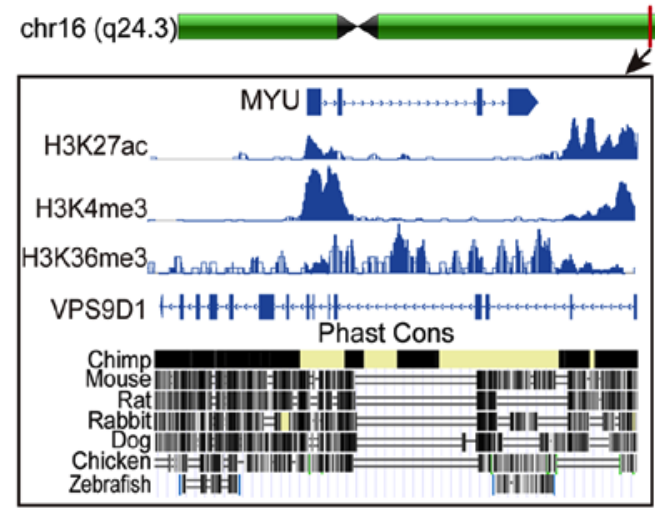

$\mathbf{F}$

phyloCSF score

G
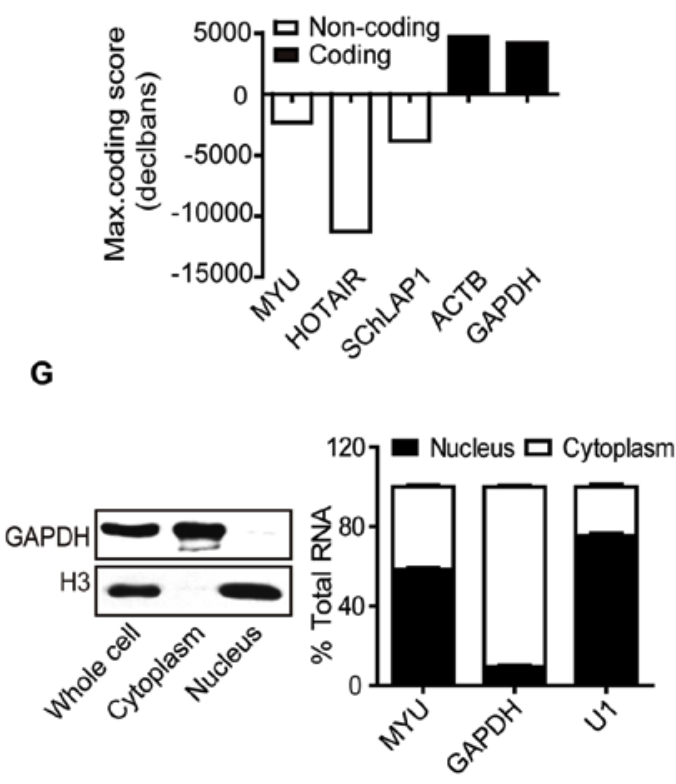

Figure 3. $M Y U$ is upregulated in PCa. (A) $M Y U$ was significantly upregulated in various cancers, including PCa (NT, normal tissues; TP, primary tumor, $\mathrm{P}<0.0001, \mathrm{n}=52)$. (B) The $M Y U$ promoters were hypomethylated in $\mathrm{PCa}(\mathrm{P}=0.0163)$. (C) ROC curve for prediction of $\mathrm{PCa}$ using $M Y U$ expression levels from TCGA. The area under the curve (AUC) was 0.906. (D) The 5' and $3^{\prime}$ end sequences of $M Y U$ in DU145 cells were determined by $5^{\prime} / 3^{\prime}-\mathrm{RACE}$. (E) Genomic landscape of $M Y U$ gene: ChIP-seq data for H3K4me3, H3K27ac, and H3K36me3 demonstrated enrichment at the $M Y U$ gene. In addition, RNA-seq data showed unconservation for $M Y U$ in 100 vertebrates revealed by UCSC Genome Browser. (F) The protein-coding potential of $M Y U$ transcript was scored by using PhyloCSF. HOTAIR and SChLAP1 were non-coding transcript controls (PhyloCSF score $<$ ). GAPDH and ACTB were coding transcript controls (PhyloCSF score $>0$ ). (G) The subcellular distribution of $M Y U$ in LNCaP cells (U1 as a nuclear marker; GAPDH as a cytoplasmic marker). Data represent the mean \pm SEM from three independent experiments $\left({ }^{*} \mathrm{P}<0.05 ;{ }^{* *} \mathrm{P}<0.01 ;{ }^{* * *} \mathrm{P}<0.001\right)$.

lncRNA, miRNA, and mRNA expression data. The expression level of lncRNA $M Y U$ in prostate adenocarcinoma (PRAD) based on the clinical information was obtained from The Cancer Genome Atlas (TCGA) (17) and the matched expression profiles of $M Y U$ in Mitranscriptome (18). TCGA PRAD patient miRNA expression (Level 3 data, illuminahiseq mirnaseq) and mRNA expression (level 3 data, RNA-seq Version 2) was download from the Broad GDAC Firehose (19).

ChIP-Seq data. Sequencing data from GSE96019, GSE96399 and GSE96418 were downloaded from GEO. Reads from the PC3 H3K4me3, H3K27ac and H3K36me3 ChIP-Seq samples were mapped to human genome version hg19 using HISAT2. Peak calling was performed using MACS (20) according to the published protocols (21). Data were visualized using the UCSC Genome Browser (22).
Statistical analysis. The data were collected and expressed as means \pm SEM. Statistical differences (P-values) between two groups were obtained by using a two-tailed Student's t-test. Statistical differences (P-values) in multiple groups were obtained by using a two-way ANOVA analysis. All experiments were carried out in triplicate. A two-tailed $\mathrm{P}<0.05$ was considered to indicate statistical significance. All statistical analyses were undertaken using GraphPad Prism 5.0 (GraphPad Software, Inc., La Jolla, CA, USA).

\section{Results}

MYU is significantly upregulated in PCa. In order to search for the differentially expressed IncRNAs associated with $\mathrm{PCa}$, we analyzed clinical patient data in TCGA and matched expression profiles of IncRNAs from Mitranscriptome. We 
A

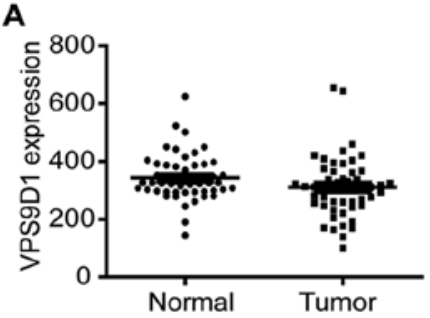

D
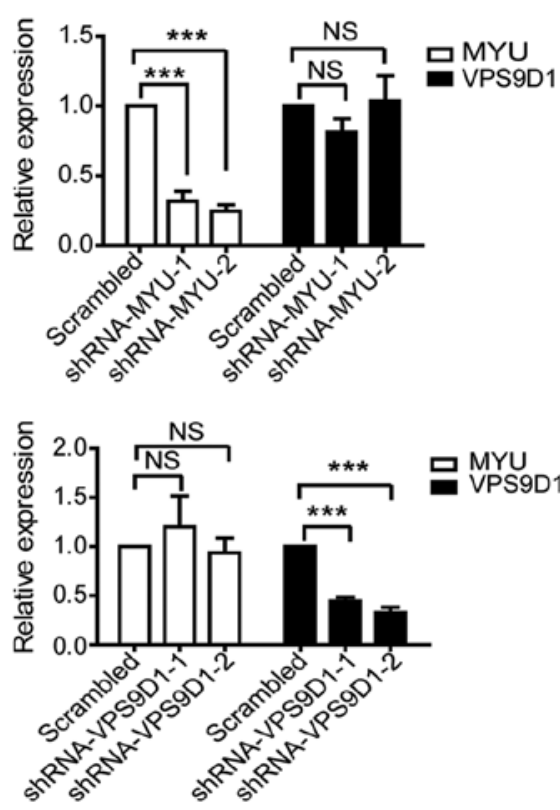

B

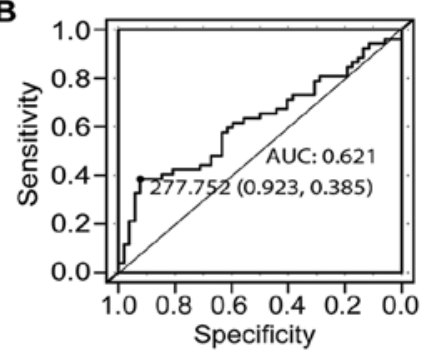

E
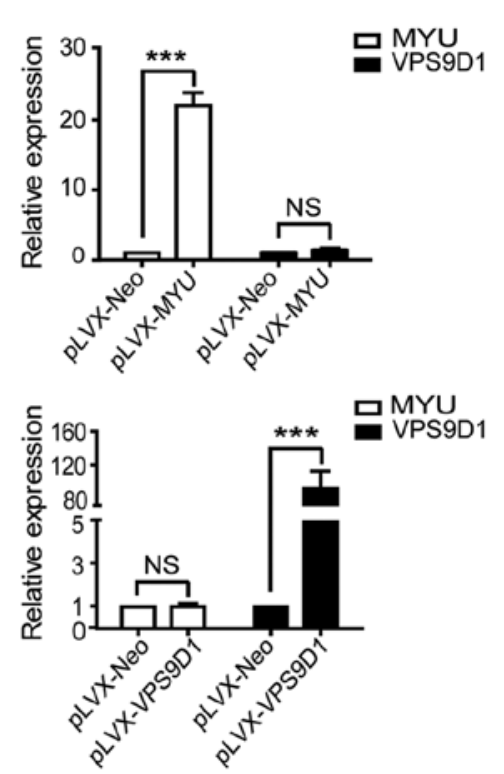

C

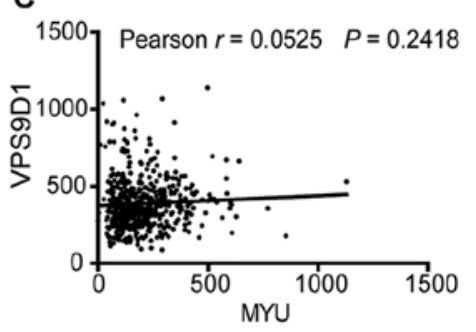

$\mathbf{F}$
G
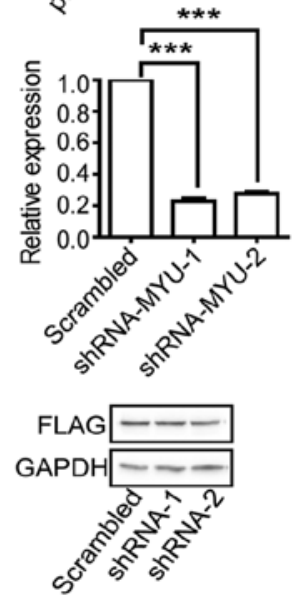

Figure 4. MYU does not regulate VPS9D1. (A) The expression of VPS9D1 in PCa samples in TCGA ( $\mathrm{P}=0.0773, \mathrm{n}=52)$. (B) The ROC curve analysis of VPS9D1. (C) The correlation analysis between $M Y U$ and VPS9D1 in PCa tissues ( $\mathrm{r}=0.0525, \mathrm{P}=0.2418$ ). (D) qRT-PCR results of the knockdown of $M Y U$ or VPS9D1 in DU145 cells. (E) qRT-PCR results of the overexpression of $M Y U$ or VPS9D1 in PC3 cells. (F) Western blotting was used to detect the expression of VPS9D1 in DU145 cells. (G) Upper panel: $M Y U$ knockdown in VPS9D1 ectopically overexpressed cells was tested by qRT-PCR. Lower panel: western blot assays were used to tested the change in VPS9D1 protein expression after knockdown of MYU in VPS9D1 ectopically overexpressed cells. The data graphs depict numbers from three independent experiments (means $\pm \mathrm{SEM} ;{ }^{*} \mathrm{P}<0.05,{ }^{* *} \mathrm{P}<0.01,{ }^{* * *} \mathrm{P}<0.001$ ). NS, not significant.

noted that lncRNA $M Y U$ was significantly upregulated in multiple cancers compared with adjacent normal tissues, and focused on $\mathrm{PCa}(\mathrm{P}<0.0001$, Fig. 3A). To investigate the potential cause of higher $M Y U$ expression in $\mathrm{PCa}$, we examined the methylation levels of the $M Y U$ promoter region, which is a major cause of gene deregulation in tumorigenesis (23). Apparently, the methylation levels of histone $\mathrm{H} 3$ of the $M Y U$ promoter region in PCa tissues was significantly lower than those of adjacent normal tissues ( $\mathrm{P}=0.0163$, Fig. 3B). Moreover, receiver operating characteristic (ROC) curve was used to evaluate the sensitivity and specificity of $M Y U$ expression in predicting PCa tissues from normal tissues. $M Y U$ displayed considerable predictive significance, with an area under the curve (AUC) of 0.906 (Fig. 3C). In summary, $M Y U$ is downregulated in $\mathrm{PCa}$ and may be a potentially diagnostic indicator.

The molecular characterization of Myu. To explore the function of $M Y U$ more precisely, we performed 5'/3'-RACE to obtain the accurate transcript of $M Y U$, which is a $1,461 \mathrm{bp}$ transcript with four exons (Fig. 3D and Fig. 1). Published PCa chromatin immunoprecipitation and sequencing (ChIP-seq) data confirmed that the transcriptional start site (TSS) of $M Y U$ was marked by H3-lysine-27-acetylation (H3K27ac) (24), H3-lysine-4-trimethylation (H3K4me3) (25) and that its gene body harbored H3-lysine-36-trimethylation (H3K36me3) (26), an epigenetic signature consistent with lncRNAs. In addition, the UCSC Genome Browser revealed that $M Y U$ sequences across the different species were extremely unconserved (Fig. 3E). The PhyloCSF analysis showed that $M Y U$ has no potential protein-coding ability (Fig. 3F). Moreover, subcellular localization of $M Y U$ showed about $58 \% M Y U$ in the nucleus in LNCaP cells (Fig. 3G). Taken together, these data revealed that $M Y U$ is an active transcribed lncRNA, which exists both in the nucleus and cytoplasm.

VPS9D1 is not regulated by MYU. We found that $M Y U$ has a corresponding sense-cognate coding gene VPS9D1 from the UCSC Genome Browser. Many studies have shown that antisense transcripts regulate the expression of sense genes, particular for ncRNAs as antisense transcripts $(27,28)$. We investigated the potential relationship between $M Y U$ and VPS9D1. There was no difference in expression levels of VPS9D1 between PCa tissues and adjacent normal tissues (Fig. 4A). The ROC analysis showed that the AUC of VPS9D1 was 0.621 (Fig. 2B). Moreover, there was no statis- 
A
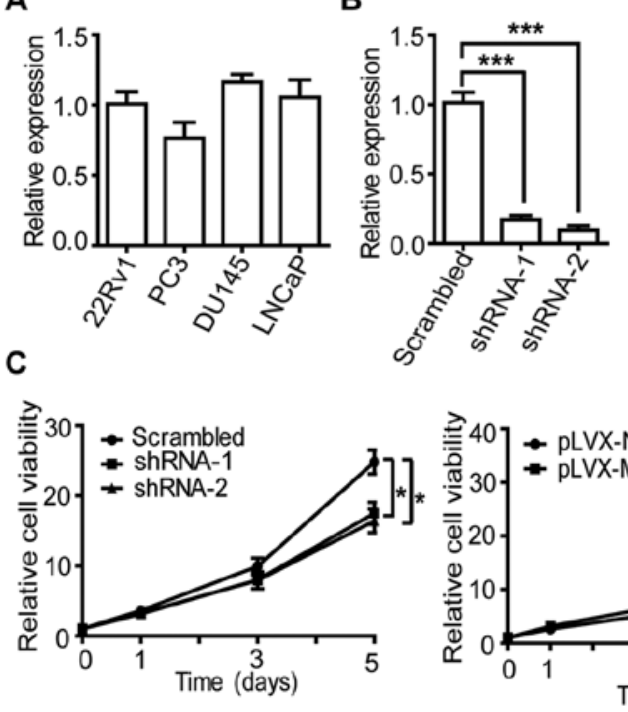

D
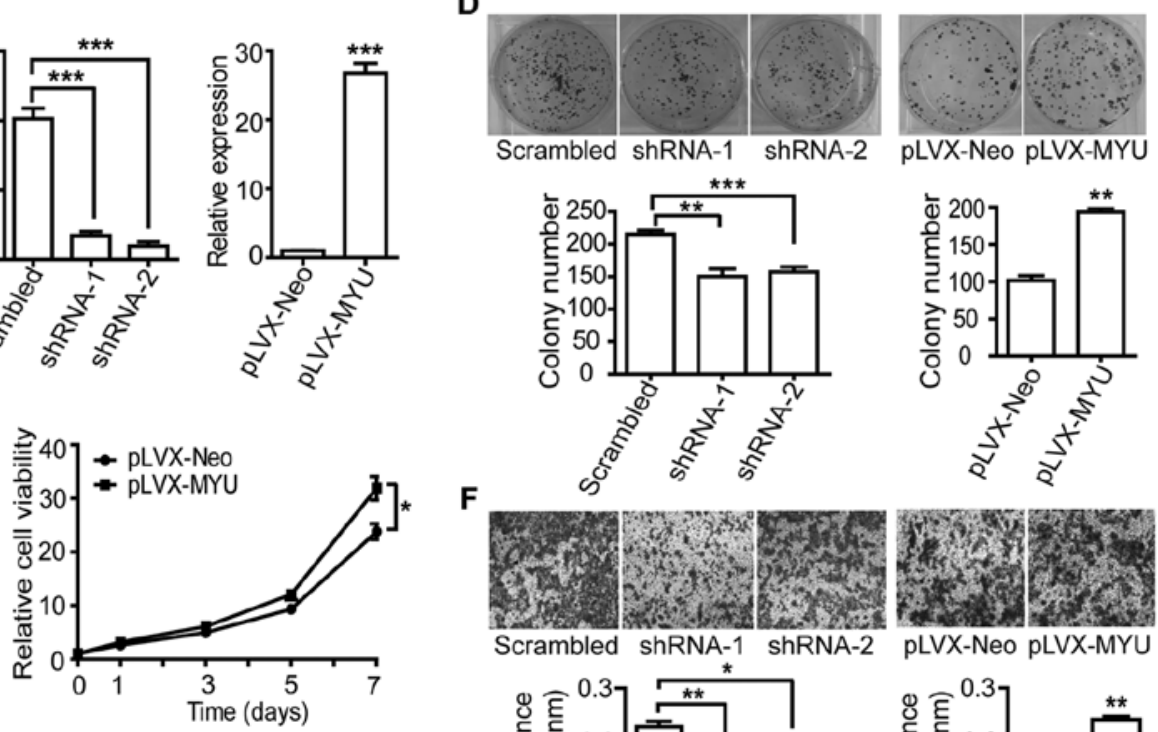

E
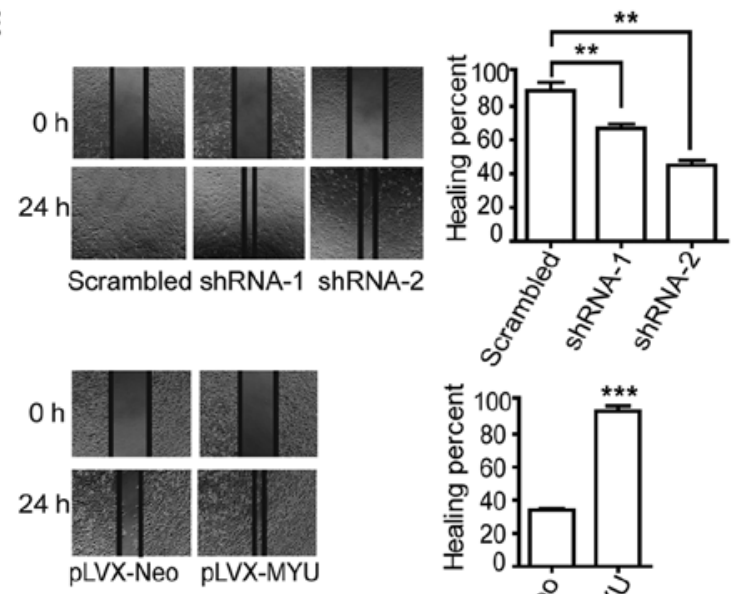
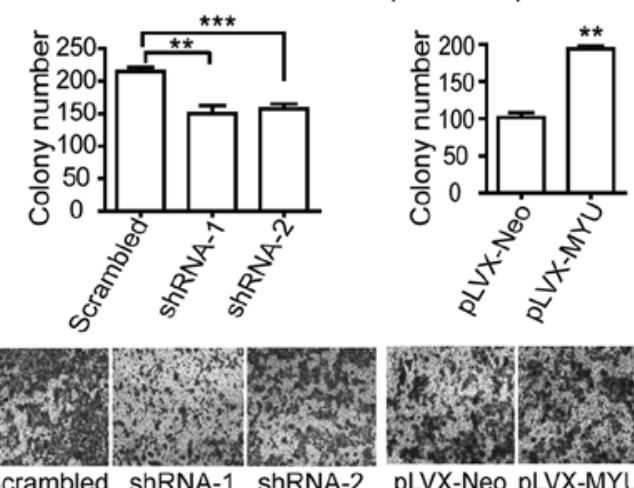

$\mathbf{F}$
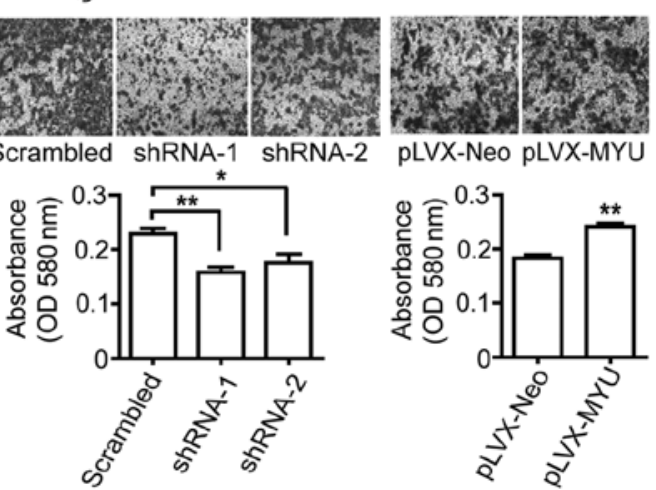

G

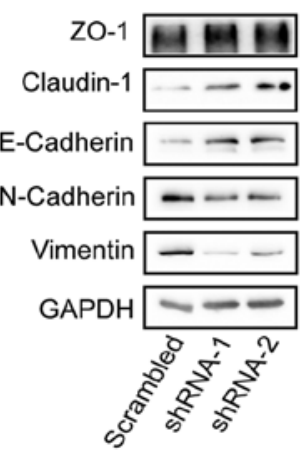

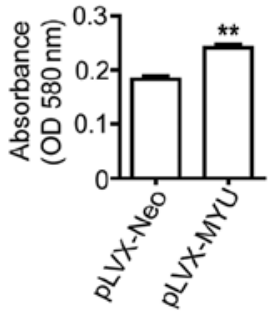

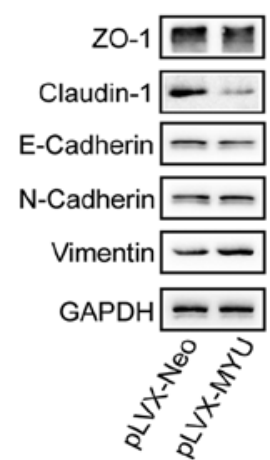

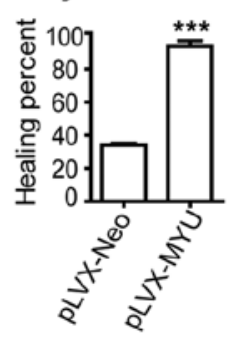

Figure 5. MYU is required for PCa cell proliferation and migration. (A) $M Y U$ in PCa cell lines (22Rv1, PC3, DU145 and LNCaP) was examined by qRT-PCR. (B) qRT-PCR analysis of $M Y U$ relative expression levels in DU145 and PC3 cells. (C) CTG assays demonstrated that depletion of $M Y U$ inhibited cell proliferation, while ectopic expression of $M Y U$ promoted cell proliferation. (D) Colony formation assays demonstrated that knockdown of $M Y U$ inhibited cell colony numbers, while ectopic expression of $M Y U$ increased cell colony numbers. (E) Wound healing assays were conducted in DU145 (knockdown) and PC3 (overexpression) cells for $24 \mathrm{~h}$ of recovery. DU145 cells were incubated with $1 \%$ serum medium and PC3 cells were incubated with serum-free medium. (F) Transwell chamber assays were conducted in DU145 (knockdown) and PC3 (overexpression) cells for 24 h. DU145 and PC3 cells were incubated with $1 \%$ serum medium. Representative graphs are shown. (G) Western blot assays were conducted to test the changes in the protein levels of epithelial-mesenchymal transition (EMT) markers in the control and $M Y U$-knockdown/overexpressed cells. ${ }^{*} \mathrm{P}<0.05 ;{ }^{* *} \mathrm{P}<0.01 ;{ }^{* * * *} \mathrm{P}<0.001$.

tically significant correlation in RNA level between $M Y U$ and VPS9D1 (r=0.0525, $\mathrm{P}=0.2418)$ (Fig. 4C). Furthermore, we examined the potential regulation between $M Y U$ and VPS9D1 using qRT-PCR and western blotting assays. The qRT-PCR results revealed that knockdown of either gene did not affect the mRNA level of another gene (Fig. 4D), and the result of overexpression was the same (Fig. 4E). In order to determine whether $M Y U$ expression affected the protein level of VPS9D1, we overexpressed VPS9D1 in DU145 cells (Fig. 4F). Then we knocked down $M Y U$ in the VPS9D1-overexpressed cells, and observed the same protein levels of VPS9D1 in either $M Y U$-knockdown or control cells (Fig. 4G). These results suggest that $M Y U$ did not regulate VPS9D1 at either the mRNA or protein level. Thus, we focused on studying lncRNA $M Y U$.
MYU promotes $P C$ a cell proliferation and migration in vitro. To evaluate the biological effects of $M Y U$ on $\mathrm{PCa}$, we firstly performed qRT-PCR to examine $M Y U$ expression level in four PCa cell lines (Fig. 5A). To clarify the function of $M Y U$, we established cell lines with stably overexpressed $M Y U$ and $M Y U$-specific shRNAs (Fig. 5B). CTG assays indicated that PCa cell proliferation was repressed by $M Y U$ shRNAs compared to that of cells stably expressing the scrambled shRNA, whereas enhancement of cell viability occurred after overexpression of $M Y U$ (Fig. 5C). In colony formation assay, $M Y U$-upregulated PC3 cells exhibited increased colony growth, while knockdown of $M Y U$ in DU145 cells reduced colony growth compared to the control cells (Fig. 5D). Additionally, wound healing (Fig. 5E), Transwell chamber (Fig. 5F) and western blotting (Fig. 5G) assays indicated that 
A

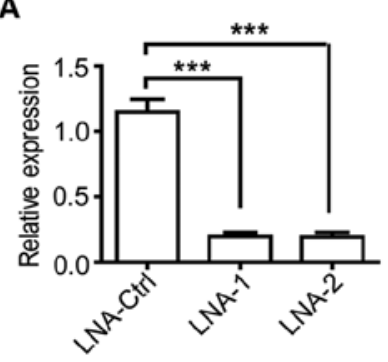

B

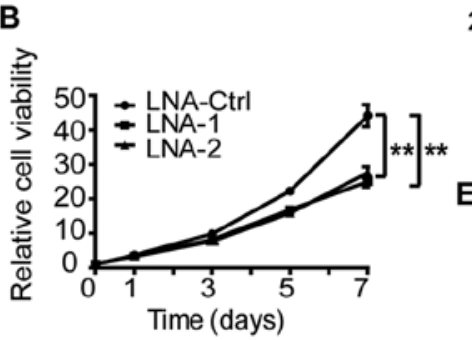

C

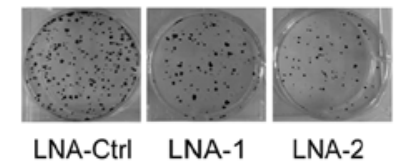

D

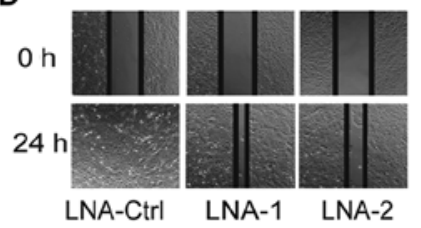

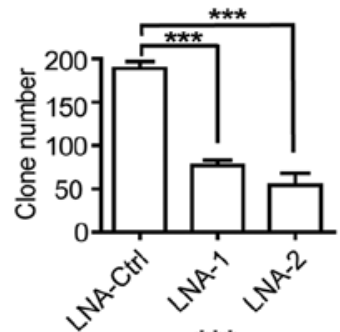

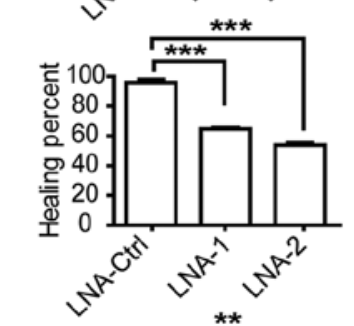

(1)

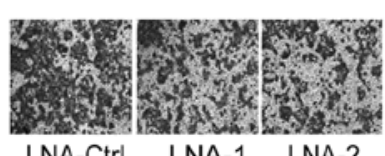

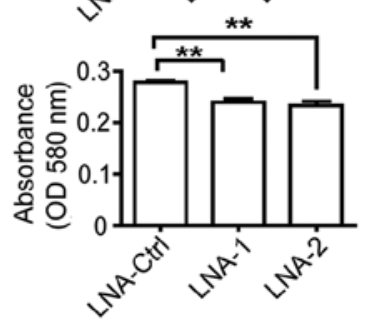

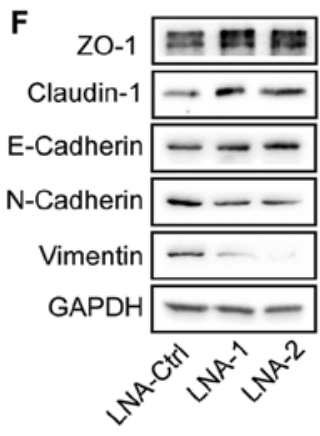

Figure 6. $M Y U$ knockdown by LNAs. (A) qRT-PCR analysis of $M Y U$ relative expression levels in DU145 cells. (B) The relative cell viability of control and $M Y U$-knockdown DU145 cells were tested by CTG assays. (C) Colony formation assays demonstrated relative colony numbers of control or $M Y U$-knockdown DU145 cells. (D) Wound healing assays were conducted in DU145 cells for $24 \mathrm{~h}$ of recovery. DU145 cells were incubated with $1 \%$ serum medium. (E) Transwell chamber assays were conducted in DU145 cells for $24 \mathrm{~h}$. DU145 cells were incubated with $1 \%$ serum medium. Representative graphs are shown. (F) Western blot assays were conducted to test the changes in the protein levels of EMT markers in control and $M Y U$-knockdown cells. Data represent the mean \pm SEM from three independent experiments. ${ }^{*} \mathrm{P}<0.05 ;{ }^{* *} \mathrm{P}<0.01 ;{ }^{* * *} \mathrm{P}<0.001$.

Table IV. Sequences of miR-184 mimics and negative control.

\begin{tabular}{ll}
\hline Mimics & \multicolumn{1}{c}{ Sequence } \\
\hline miR-184 mimics & 5' UGGACGGAGAACUGAUAAGGGU 3' \\
Negative control & 5' UUCUCCGAACGUGUCACGUTT 3'
\end{tabular}

knockdown of $M Y U$ reduced the DU145 cell migration rate and the protein level of $\mathrm{N}$-cadherin and vimentin, but increased ZO-1, claudin-1 and E-cadherin. In contrast, overexpression of $M Y U$ in the $\mathrm{PC} 3$ cells resulted in a higher migration rate, accompanied by downregulated $\mathrm{ZO}-1$, claudin-1 and E-cadherin and upregulated $\mathrm{N}$-cadherin and vimentin. To further confirm these results, we also used locked nucleic acids (LNAs) to knock down the expression of $M Y U$. Similar results for cell viability, clonogenicity and motility were obtained in the DU145 cells (Fig. 6A-F). These results suggest that $M Y U$ may act as a non-coding oncogene in PCa cells.

MYU upregulates $c-M y c$ expression by competitively binding $m i R-184$. We aimed to ascertain the potential underlying mechanism of $M Y U$, which may mediate PCa progression. lncRNAs are known to work as sponges to recruit miRNAs, resulting in the activation of miRNA target genes $(13,29)$. We analyzed the correlation of the expression level between $M Y U$ and mature miRNAs and found that $M Y U$ showed a significantly negative correlation with 15 miRNAs $(\mathrm{r}<-0.3$, $\mathrm{P}<0.0001$, Table V). We then tested if three miRNAs including
Table V. Fifteen miRNAs show significantly negative correlation with MYU in TCGA PCa tissues (Spearman $\mathrm{r}<-0.3$, $\mathrm{P}<0.0001)$.

\begin{tabular}{lll}
\hline miRNA & Spearman r & P-value \\
\hline hsa.miR.187.3p & -0.420633196 & $1.14 \mathrm{E}-10$ \\
hsa.miR.221.3p & -0.40755072 & $4.74 \mathrm{E}-10$ \\
hsa.miR.143.3p & -0.395310718 & $1.71 \mathrm{E}-09$ \\
hsa.miR.873.5p & -0.369065673 & $2.25 \mathrm{E}-08$ \\
hsa.miR.187.5p & -0.365681346 & $3.09 \mathrm{E}-08$ \\
hsa.miR.184 & -0.3619539 & $4.36 \mathrm{E}-08$ \\
hsa.miR.378c & -0.359757081 & $5.33 \mathrm{E}-08$ \\
hsa.miR.222.3p & -0.350223717 & $1.25 \mathrm{E}-07$ \\
hsa.miR.222.5p & -0.349057455 & $1.39 \mathrm{E}-07$ \\
hsa.miR.23c & -0.343942199 & $2.16 \mathrm{E}-07$ \\
hsa.miR.27b.3p & -0.334526294 & $4.81 \mathrm{E}-07$ \\
hsa.miR.133b & -0.332952086 & $5.48 \mathrm{E}-07$ \\
hsa.miR.767.5p & -0.327593572 & $8.51 \mathrm{E}-07$ \\
hsa.miR.452.5p & -0.31499159 & $2.32 \mathrm{E}-06$ \\
hsa.miR.152.3p & -0.306935385 & $4.30 \mathrm{E}-06$ \\
\hline
\end{tabular}

miR-187-3p, miR-143-3p and miR-184 ( $\mathrm{r}<-0.35, \mathrm{P}<0.0001)$ can bind to $M Y U$. The dual luciferase reporter assays revealed that only miR-184 downregulated the luciferase activity of lncRNA $M Y U$. Then, we searched the reported target coding genes of miR-184 in PubMed. Noteworthy, miR-184 has been reported 
A

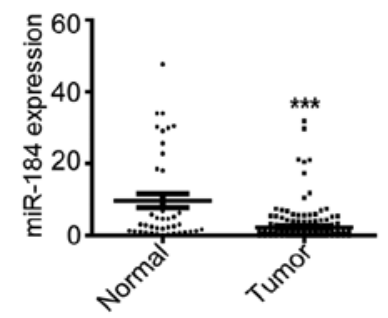

B

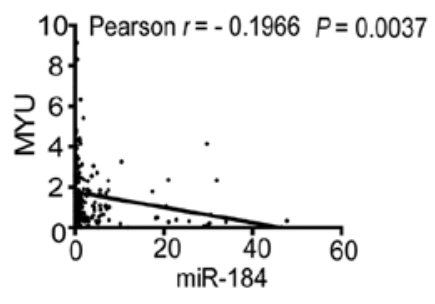

C

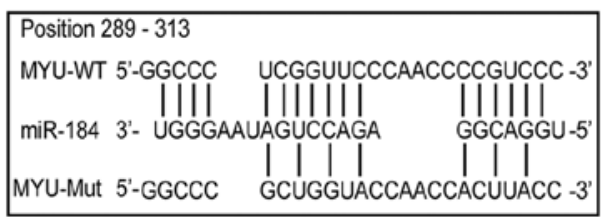

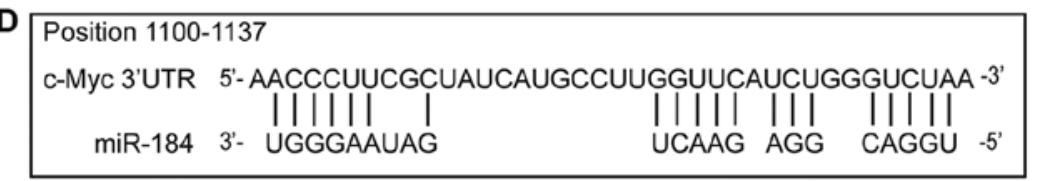

E

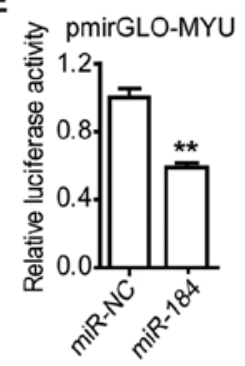

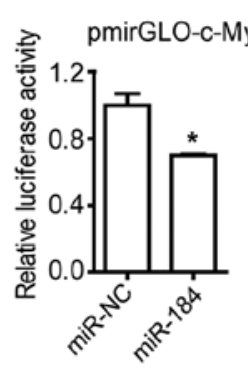

pmirGLO

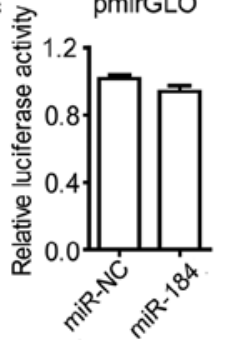

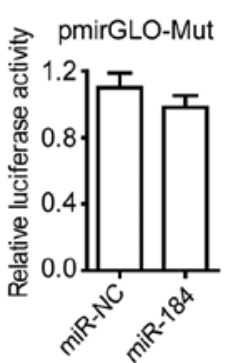

$\mathbf{F}$

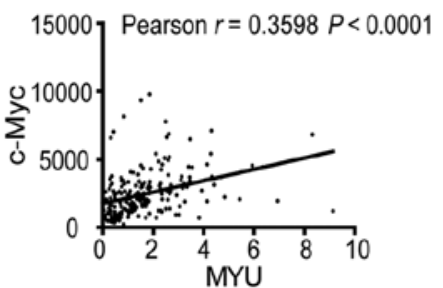

G

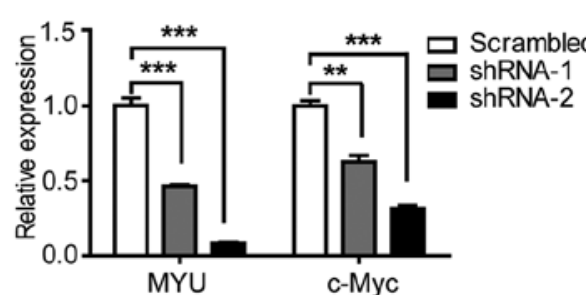

H

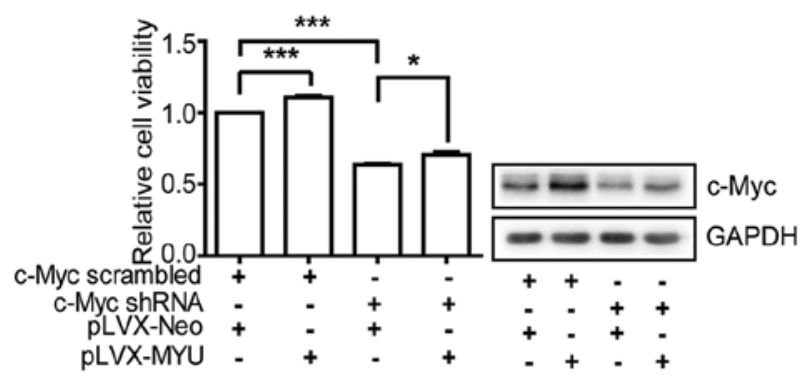

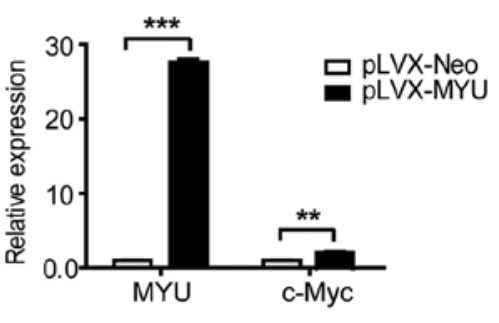

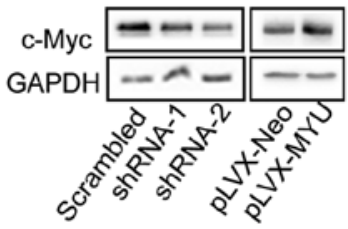

I

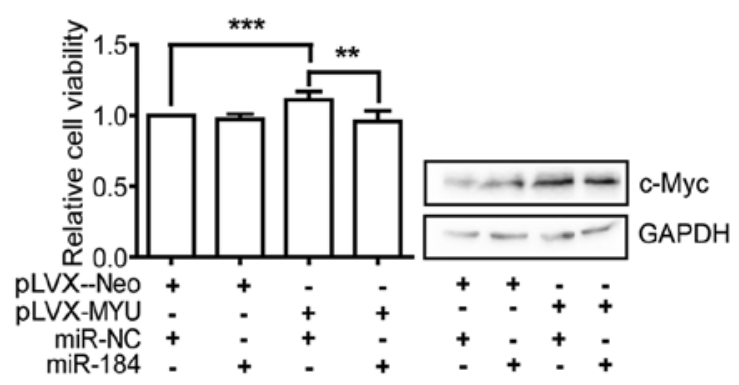

Figure 7. MYU upregulates c-Myc by binding to miR-184. (A) The expression of miRNA is significantly downregulated in TCGA PCa tissues. (B) The correlation analysis between $M Y U$ and miR-184 in 216 TCGA PCa tissues ( $(\mathrm{r}=-0.1966, \mathrm{P}<0.0037)$. (C) Putative $M Y U$ base pairing with miR-184 as identified by target prediction algorithms RNAhybrid. (D) Putative c-Myc 3'UTR base pairing with miR-184 as identified by target prediction algorithms. (E) Luciferase activities in Lenti- ${ }^{\mathrm{TM}} 293 \mathrm{~T}$ cells co-transfected with miR-184 and dual luciferase reporter gene containing nothing, MYU or mutant and c-Myc 3'UTR. Data are presented as the relative ratio of the firefly to Renilla luciferase activity. (F) The correlation analysis between MYU and c-Myc expression in 216 TCGA PCa tissues ( $\mathrm{r}=0.3598, \mathrm{P}<0.0001)$. (G) qRT-PCR and western blot analysis of c-Myc expression level in MYU knockdown or overexpressed cells. (H) CTG assays showed that knockdown of c-Myc limited the enhanced viability in $M Y U$-overexpressing PCa cells. Western blot analyses confirmed the c-Myc expression levels. (I) CTG assays found that miR-184 mimic overexpression repressed the cell viability in overexpressed MYU PCa cells. Western blot showed that miR-184 overexpression reduced the protein level of c-Myc in $M Y U$-overexpressing cells. The data graphs depict the count number from three independent experiments (means $\pm \mathrm{SEM} ;{ }^{*} \mathrm{P}<0.05,{ }^{* *} \mathrm{P}<0.01,{ }^{* * *} \mathrm{P}<0.001$ ).

as a tumor-suppressor gene in multiple cancers $(30,31)$, and downregulated c-Myc expression $(32,33)$. It has been reported that $M Y U$ is a direct target of c-Myc (14). We hypothesized that $M Y U$ may promote the proliferation of $\mathrm{PCa}$ as a ceRNA to sponge miR-184, thus upregulating c-Myc.

TCGA data revealed that miR-184 was significantly downregulated in PCa tissues (Fig. 7A) and negatively correlated with $M Y U$ (r=-0.1966, $\mathrm{P}=0.0037)$ (Fig. 7B). RNAhybrid (34) was used to predict the binding sites of miR-184/MYU and miR-184/3' UTR of c-Myc (Fig. 7C and D). We constructed luciferase reporters containing full-length $M Y U$ or mutated miR-184 binding sites or 3' UTR of c-Myc. We found that overexpression of miR-184 mimic (Table IV) reduced luciferase activity of $M Y U$ and c-Myc 3'UTR, but not of the empty vector 
A

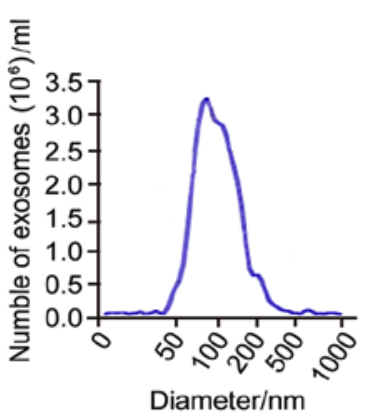

E

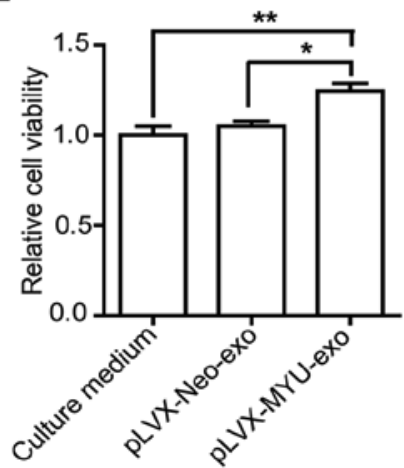

B

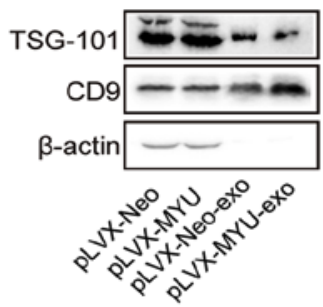

$\mathbf{F}$

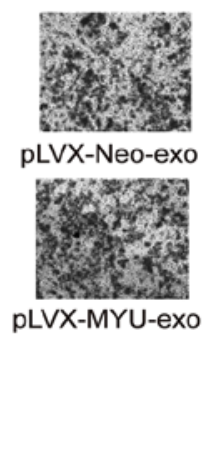

C

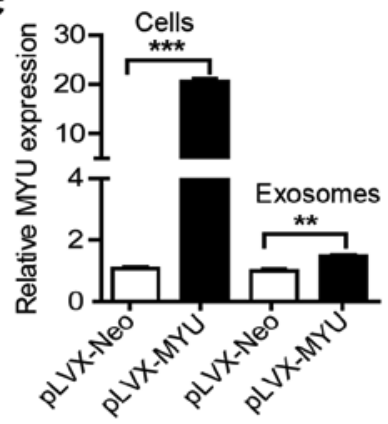

$\mathbf{G}$

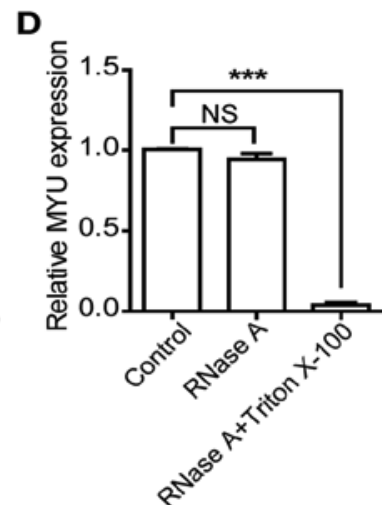

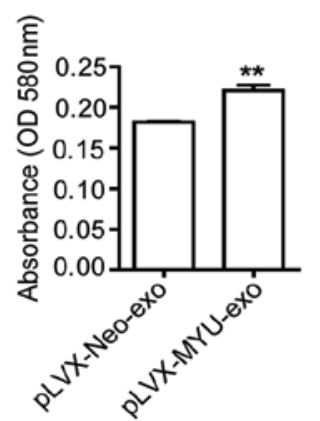

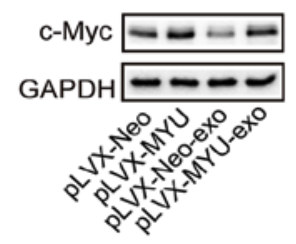

Figure 8. Exosome-contained $M Y U$ functions in PCa cells. (A) NanoSight particle analysis showing the size and number of exosomes. (B) Western blot analysis confirmed exosomal purity by detecting TSG-101, CD9, and $\beta$-actin. (C) qRT-PCR analysis of $M Y U$ from $M Y U$-overexpressing or control PC3 cells and exosomes. (D) qRT-PCR analysis of $M Y U$ from exosomes treated with RNase A $(50 \mu \mathrm{g} / \mathrm{ml})$ alone or combined with Triton X-100 (0.1\%) (P<0.0001) for 40 min. (E) The relative viability of PC3 cells fed with the exosomes derived from the cells overexpressing $M Y U$ or control. (F) The relative migration of PC3 cells that were incubated with exosomes derived from $M Y U$-overexpressing or the control PC3 cells, respectively. Representative graphs are shown. (G) Western blotting demonstrated the c-Myc protein level of PC3 cells fed with the exosomes derived from the cells overexpressing $M Y U$ or empty vector. Data represent the mean \pm SEM from three independent experiments $\left({ }^{*} \mathrm{P}<0.05 ;{ }^{* *} \mathrm{P}<0.01 ;{ }^{* * *} \mathrm{P}<0.001\right)$. NS, not significant.

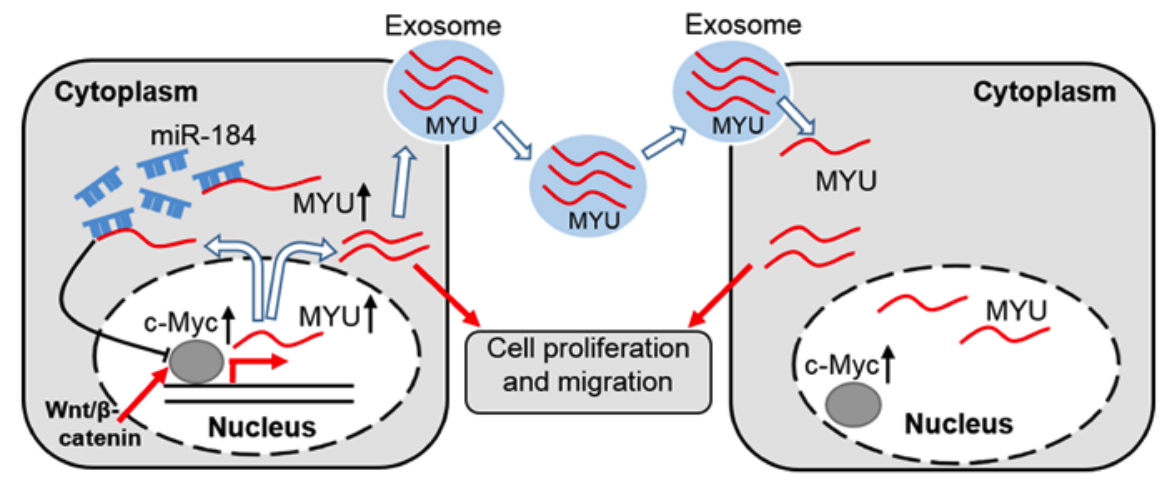

Figure 9. A schematic model of lncRNA $M Y U$ functions in PCa cells. lncRNA $M Y U$, which is upregulated in PCa tissues, promotes PCa cell proliferation and migration. Furthermore, $M Y U$ can be packaged into exosomes and function in recipient cells. Mechanistically, $M Y U$ upregulates c-Myc expression by competitively binding miR-184.

or the mutated reporter vector (Fig. 7E). Next, we explored the effect of $M Y U$ on the expression of c-Myc. The expression level of c-Myc was positively correlated with $M Y U(\mathrm{r}=0.3598$, $\mathrm{P}<0.0001$ ) in PCa tissues (Fig. 7F). Furthermore, we detected that $M Y U$ knockdown in DU145 cells decreased the mRNA and protein level of c-Myc. Inversely, $M Y U$ overexpression in PC3 cells increased c-Myc expression (Fig. 7G). In addition, c-Myc knockdown suppressed the proliferation of PC3 cells and inhibited the effect of $M Y U$ overexpression on promoting cell proliferation. Additionally, the protein level of c-Myc was consistent with the cell proliferation (Fig. $7 \mathrm{H})$, indicating that
c-Myc can partly influence $M Y U$. To further clarify the relationship of $M Y U$, miR-184 and c-Myc, we transfected miR-184 mimics into $M Y U$-overexpressing PC3 cells. We found that overexpression of miR-184 significantly abrogated the effect of $M Y U$ overexpression on promoting cell proliferation and suppressed the protein level of c-Myc (Fig. 7I). On the base of the above findings, $M Y U$ likely regulates c-Myc by functioning as ceRNA to sponge miR-184.

Intercellular transfer of MYU by exosome functions in $\mathrm{PCa}$ cells. Recent studies suggest that exosomes, which contain 
proteins, mRNAs, miRNAs and lncRNAs, may participate in the biological effects in cancer cells $(35,36)$. To examine whether $M Y U$ is present in exosomes, we isolated exosomes from the culture medium of $M Y U$-overexpressing or control PC 3 cells. Nanosight particle tracking analysis demonstrated the size and number of exosomes (Fig. 8A). Western blot analysis further confirmed their identity by the exosomal markers TSG-101 and CD9 (Fig. 8B). We detected the expression level of $M Y U$ by qRT-PCR in the exosomes of both PC3 cell lines. There was a significant upregulation of $M Y U$ in the exosomes isolated from the $M Y U$-overexpressing cells, which was consistent with the cellular expression (Fig. 8C). We next investigated the existing pattern of $M Y U$ from exosomes. The levels of $M Y U$ were unchanged upon RNase A treatment but significantly decreased after being treated with RNase A and Triton X-100 (Fig. 8D), indicating that $M Y U$ was mainly wrapped by the membrane of exosomes. These findings suggest that $M Y U$ can be delivered into the extracellular milieu by exosomes. In order to explore whether exosome-contained $M Y U$ can function in neighboring cells, we purified exosomes and then fed PC3 cells. The CTG (Fig. 8E) and Transwell chamber assays (Fig. 8F) demonstrated that exosomes from the $M Y U$-overexpressing PC3 cells significantly increased proliferation and migration ability of recipient cells, compared to those from control cells. Correspondingly, the c-Myc protein level was significantly increased in the recipient PC3 cells fed with exosomes from the $M Y U$-overexpressing cells (Fig. 8G). These findings suggest that $M Y U$ can be delivered into the extracellular milieu by exosomes, and then function in other PCa cells.

\section{Discussion}

In the present study, we found that $M Y U$ promotes PCa cell proliferation, migration and the exosome is the carrier for extracellular $M Y U$. Mechanistically, $M Y U$ likely promotes proliferation of PCa cells by competitively binding miR-184, increasing the expression of c-Myc (Fig. 9).

$M Y U$ is expressed in various tumors with a broad spectrum. MYU has been reported to regulate CRC based on its annotated sequence $(14,15)$. However, its future application may be limited due to the lack of an accurate transcript. Generally, IncRNAs play oncogenic or suppressive roles in the biological processes of cancer through various mechanisms $(37,38)$. A recent study indicates that the expression of $M Y U$ in CRC is higher than that noted in normal tissues and shortens overall survival time (15). However, Chen et al found that the deregulation of $M Y U$ can be used as an indicator for predicting poor overall and disease-free survival of GC patients (16). These results showed that $M Y U$ plays different roles in CRC and GC. In this study, we found that $M Y U$ likely promotes $\mathrm{PCa}$ cell proliferation and migration. Therefore, $M Y U$ may function as an oncogene in PCa.

The exosome is a discoid vesicle that is $40-150 \mathrm{~nm}$ in diameter and is released into the extracellular milieu upon fusion with the cellular membrane (39). Exosomes participate in intercellular communication by transmitting intracellular cargoes, such as proteins and nucleic acids (40). A recent study reported that lncRNAs are present in exosomes and account for $20.19 \%$ of exosomal RNA extracted from the plasma of castration-resistant PCa patients (41). In this study, we detected that lncRNA $M Y U$ exists in the extracellular milieu of PC3 cells, which can be wrapped by exosomes, and promotes recipient cell proliferation and migration. Overall, $M Y U$ functions in the extracellular milieu of PCa cells by exosome transportation.

LncRNAs act as ceRNAs to sponge miRNAs leading to release of downstream target genes, which was a canonical model to study the molecular mechanism of IncRNAs $(12,13)$. In this study, we found that $M Y U$ likely upregulates c-Myc expression by sponging miR-184 (Fig. 9). A recent report demonstrated that $M Y U$ is a direct target lncRNA of the Wnt/c-Myc pathway and participates in the tumorigenicity of colon cancer cells (14). These results indicate that $M Y U$ and c-Myc may form a feedback loop to regulate each other. In conclusion, we demonstrated that $M Y U$ displays oncogenic activity by regulating c-Myc expression in $\mathrm{PCa}$, suggesting that $M Y U$ maybe as a potential diagnostic predictor and therapeutic target for $\mathrm{PCa}$.

\section{Acknowledgements}

\section{Not applicable.}

\section{Funding}

This work was supported by grants from the National Natural Science Foundation of China (81773023 and 81472827), the National Key R\&D Program of China (2016YFC1302100), Hundred-Talent Program (Y521031102) and Frontier Research Program (QYZDB-SSW-SMC038) of the Chinese Academy of Sciences to SG.

\section{Availability of data and materials}

The datasets used during the present study are available from the corresponding author upon reasonable request.

\section{Authors' contributions}

SG and JW conceived and designed the study. JW performed the experiments. JW and SG wrote the paper. All authors read and approved the manuscript and agree to be accountable for all aspects of the research in ensuring that the accuracy or integrity of any part of the work are appropriately investigated and resolved.

\section{Ethics approval and consent to participate}

Not applicable.

\section{Patient consent for publication}

Not applicable.

\section{Competing interests}

The authors declare that they have no competing interests. 


\section{References}

1. Ferlay J, Shin HR, Bray F, Forman D, Mathers C and Parkin DM Estimates of worldwide burden of cancer in 2008: GLOBOCAN 2008. Int J Cancer 127: 2893-2917, 2010.

2. Cheng W, Zhang Z and Wang J: Long noncoding RNAs: New players in prostate cancer. Cancer Lett 339: 8-14, 2013.

3. Hawksworth D, Ravindranath L, Chen Y, Furusato B, Sesterhenn IA, McLeod DG, Srivastava S and Petrovics G: Overexpression of C-MYC oncogene in prostate cancer predicts biochemical recurrence. Prostate Cancer Prostatic Dis 13: 311-315, 2010.

4. Prensner JR, Chen W, Han S, Iyer MK, Cao Q, Kothari V, Evans JR, Knudsen KE, Paulsen MT, Ljungman M, et al: The long non-coding RNA PCAT-1 promotes prostate cancer cell proliferation through cMyc. Neoplasia 16: 900-908, 2014.

5. Chang C, Liu J, He W, Qu M, Huang X, Deng Y, Shen L, Zhao X, $\mathrm{Guo} \mathrm{H}$, Jiang J et al: A regulatory circuit HP1gamma/miR-451a/cMyc promotes prostate cancer progression. Oncogene 37: 415-426, 2018

6. Zhang C, Wang L, Wang X and Gao S: The mystery of 'junk' DNA. Chin Sci Bull 61: 3079-3084, 2016.

7. Adams BD, Anastasiadou E, Esteller M, He L and Slack FJ: The Inescapable Influence of Noncoding RNAs in Cancer. Cancer Res 75: 5206-5210, 2015.

8. Schwarzer A, Emmrich S, Schmidt F, Beck D, Ng M, Reimer C, Adams FF, Grasedieck S, Witte D, Käbler S, et al: The non-coding RNA landscape of human hematopoiesis and leukemia. Nat Commun 8: 218-234, 2017.

9. Merola R, Tomao L, Antenucci A, Sperduti I, Sentinelli S, Masi S, Mandoj C, Orlandi G, Papalia R, et al: PCA3 in prostate cancer and tumor aggressiveness detection on 407 high-risk patients: a National Cancer Institute experience. J Exp Clin Cancer Res 34: $15-20,2015$.

10. Prensner JR, Iyer MK, Sahu A, Asangani IA, Cao Q, Patel L, Vergara IA, Davicioni E, Erho N, Ghadessi M, et al: The long noncoding RNA SChLAP1 promotes aggressive prostate cancer and antagonizes the SWI/SNF complex. Nat Genet 45: 1392-1398, 2013.

11. Parolia A,Crea F, Xue H, Wang Y, Mo F, Ramnarine VR, Liu HH, Lin D, Saidy NR, Clermont PL, et al: The long non-coding RNA PCGEM1 is regulated by androgen receptor activity in vivo. Mol Cancer 14: 46-52, 2015.

12. Liu XH, Sun M, Nie FQ, Ge YB, Zhang EB, Yin DD, Kong R, Xia R, Lu KH, Li JH, et al: Lnc RNA HOTAIR functions as a competing endogenous RNA to regulate HER2 expression by sponging miR331-3p in gastric cancer. Mol Cancer 13: 92-105, 2014

13. Fang C, Qiu S, Sun F, Li W, Wang Z, Yue B, Wu X and Yan D: Long non-coding RNA HNF1A-AS1 mediated repression of miR-34a/SIRT1/p53 feedback loop promotes the metastatic progression of colon cancer by functioning as a competing endogenous RNA. Cancer Lett 410: 50-62, 2017.

14. Kawasaki Y, Komiya M, Matsumura K, Negishi L, Suda S, Okuno M, Yokota N, Osada T, Nagashima T, Hiyoshi M, et al: MYU, a target lncRNA for Wnt/c-Myc signaling, mediates induction of CDK6 to promote cell cycle progression. Cell Reports 16: 2554-2564, 2016.

15. Yang L, Xu L, Wang Q, Wang M and An G: Dysregulation of long non-coding RNA profiles in human colorectal cancer and its association with overall survival. Oncol Lett 12: 4068-4074, 2016.

16. Chen M, Wu X, Ma W, Zhou Q, Wang X, Zhang R, Wang J and Yang X: Decreased expression of 1ncRNA VPS9D1-AS1 in gastric cancer and its clinical significance. Cancer Biomark 21 23-28, 2017.

17. Weinstein JN, Collisson EA, Mills GB, Shaw KR, Ozenberger BA, Ellrott K, Shmulevich I, Sander C and Stuart JM; Cancer Genome Atlas Research Network: The Cancer Genome Atlas Pan-Cancer analysis project. Nat Genet 45: 1113-1120, 2013.

18. Iyer MK, Niknafs YS, Malik R, Singhal U, Sahu A, Hosono Y, Barrette TR, Prensner JR, Evans JR, Zhao S, et al: The landscape of long noncoding RNAs in the human transcriptome. Nat Genet 47: 199-208, 2015.

19. Cheng PF, Dummer R and Levesque MP: Data mining The Cancer Genome Atlas in the era of precision cancer medicine. Swiss Med Wkly 145: w14183, 2015

20. Zhang Y, Liu T, Meyer CA, Eeckhoute J, Johnson DS, Bernstein BE, Nusbaum C, Myers RM, Brown M, Li W, et al: Model-based analysis of ChIP-Seq (MACS). Genome Biol 9: R137, 2008 .

21. Feng J, Liu T and Zhang Y: Using MACS to identify peaks from ChIP-Seq data. Curr Protoc Bioinformatics Chapter 2: Unit2.14, 2011.
22. Kent WJ, Sugnet CW, Furey TS, Roskin KM, Pringle TH, Zahler AM and Haussler D: The human genome browser at UCSC. Genome Res 12: 996-1006, 2002.

23. Liang $G$ and Weisenberger DJ: DNA methylation aberrancies as a guide for surveillance and treatment of human cancers. Epigenetics 12: 416-432, 2017.

24. Creyghton MP, Cheng AW, Welstead GG, Kooistra T, Carey BW, Steine EJ, Hanna J, Lodato MA, Frampton GM, Sharp PA, et al: Histone H3K27ac separates active from poised enhancers and predicts developmental state. Proc Natl Acad Sci USA 107: 21931-21936, 2010

25. Liu X, Wang C, Liu W, Li J, Li C, Kou X, Chen J, Zhao Y, Gao H, Wang H, et al: Distinct features of H3K4me3 and H3K27me3 chromatin domains in pre-implantation embryos. Nature 537: 558-562, 2016.

26. Pokholok DK, Harbison CT, Levine S, Cole M, Hannett NM, Lee TI, Bell GW, Walker K, Rolfe PA, Herbolsheimer E, et al: Genome-wide map of nucleosome acetylation and methylation in yeast. Cell 122: 517-527, 2005.

27. Huang B, Song JH, Cheng Y, Abraham JM, Ibrahim S, Sun Z, $\mathrm{Ke} X$ and Meltzer SJ: Long non-coding antisense RNA KRT7-AS is activated in gastric cancers and supports cancer cell progression by increasing KRT7 expression. Oncogene 35: 4927-4936, 2016

28. Sun J, Wang X, Fu C, Wang X, Zou J, Hua H and Bi Z: Long noncoding RNA FGFR3-AS1 promotes osteosarcoma growth through regulating its natural antisense transcript FGFR3. Mol Biol Rep 43: 427-436, 2016.

29. Yuan JH, Yang F, Wang F, Ma JZ, Guo YJ, Tao QF, Liu F, Pan W, Wang TT, Zhou CC, et al: A long noncoding RNA activated by TGF- $\beta$ promotes the invasion-metastasis cascade in hepatocellular carcinoma. Cancer Cell 25: 666-681, 2014.

30. Emdad L, Janjic A, Alzubi MA, Hu B, Santhekadur PK, Menezes ME, Shen XN, Das SK, Sarkar D and Fisher PB Suppression of miR-184 in malignant gliomas upregulates SND1 and promotes tumor aggressiveness. Neuro-oncol 17: 419-429, 2015.

31. Cheng Z, Wang HZ, Li X, Wu Z, Han Y, Li Y, Chen G, Xie X, Huang Y, Du Z, et al: MicroRNA-184 inhibits cell proliferation and invasion, and specifically targets TNFAIP2 in Glioma. J Exp Clin Cancer Res 34: 27, 2015.

32. Wang YB, Zhao XH, Li G, Zheng JH and Qiu W: MicroRNA-184 inhibits proliferation and promotes apoptosis of human colon cancer SW480 and HCT116 cells by downregulating C-MYC and BCL-2. J Cell Biochem 119: 1702-1715, 2018.

33. Zhen Y, Liu Z, Yang H, Yu X, Wu Q, Hua S, Long X, Jiang Q, Song Y, Cheng C, et al: Tumor suppressor PDCD4 modulates miR-184-mediated direct suppression of C-MYC and BCL2 blocking cell growth and survival in nasopharyngeal carcinoma. Cell Death Dis 4: e872, 2013.

34. Bhattacharjya S, Roy KS, Ganguly A, Sarkar S, Panda CK, Bhattacharyya D, Bhattacharyya NP and Roychoudhury S: Inhibition of nucleoporin member Nup214 expression by miR-133b perturbs mitotic timing and leads to cell death. Mol Cancer 14: 42-56, 2015.

35. Qu L, Ding J, Chen C, Wu ZJ, Liu B, Gao Y, Chen W, Liu F, Sun W, Li XF, et al: Exosome-transmitted lncARSR promotes sunitinib resistance in renal cancer by acting as a competing endogenous RNA. Cancer Cell 29: 653-668, 2016.

36. Gao Y, Huang KH, Tang Y, Huang Y and Gao S: Exosome: A rising star in the era of precision oncology. Chin Sci Bull 63: $1-8,2018$.

37. He W, Zhong G, Jiang N, Wang B, Fan X, Chen C, Chen X, Huang $\mathbf{J}$ and Lin T: Long noncoding RNA BLACAT2 promotes bladder cancer-associated lymphangiogenesis and lymphatic metastasis. J Clin Invest 128: 861-875, 2018.

38. Marín-Béjar O, Mas AM, González J, Martinez D, Athie A, Morales X, Galduroz M, Raimondi I, Grossi E, Guo S, et al: The human lncRNA LINC-PINT inhibits tumor cell invasion through a highly conserved sequence element. Genome Biol 18: 202-216, 2017.

39. Théry C: Exosomes: Secreted vesicles and intercellular communications. F1000 Biol Rep 3: 15-22, 2011.

40. Melo SA, Sugimoto H, O'Connell JT, Kato N, Villanueva A, Vidal A, Qiu L, Vitkin E, Perelman LT, Melo CA, et al: Cancer exosomes perform cell-independent microRNA biogenesis and promote tumorigenesis. Cancer Cell 26: 707-721, 2014.

41. Huang X, Yuan T, Liang M, Du M, Xia S, Dittmar R, Wang D, See W, Costello BA, Quevedo F, et al: Exosomal miR-1290 and miR-375 as prognostic markers in castration-resistant prostate cancer. Eur Urol 67: 33-41, 2015. 